\title{
Microscopic Analysis of Irradiated AGR-1 Coated Particle Fuel Compacts
}

\section{HTR 2012}

\author{
Scott A. Ploger \\ Paul A. Demkowicz \\ John D. Hunn \\ Jay S. Kehn
}

October 2012

The INL is a

U.S. Department of Energy

National Laboratory

operated by

Battelle Energy Alliance

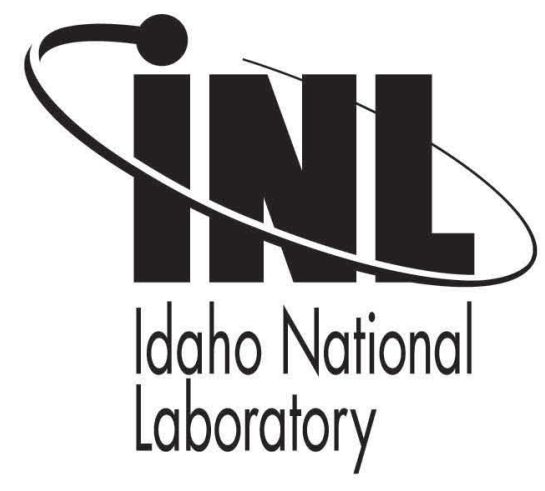

This is a preprint of a paper intended for publication in a journal or proceedings. Since changes may be made before publication, this preprint should not be cited or reproduced without permission of the author. This document was prepared as an account of work sponsored by an agency of the United States Government. Neither the United States Government nor any agency thereof, or any of their employees, makes any warranty, expressed or implied, or assumes any legal liability or responsibility for any third party's use, or the results of such use, of any information, apparatus, product or process disclosed in this report, or represents that its use by such third party would not infringe privately owned rights. The views expressed in this paper are not necessarily those of the United States Government or the sponsoring agency. 


\title{
Microscopic Analysis of Irradiated AGR-1 Coated Particle Fuel Compacts
}

\author{
Scott A. Ploger, Paul A. Demkowicz, John D. Hunn ${ }^{1}$, Jay S. Kehn ${ }^{1}$ \\ Idaho National Laboratory \\ P.O. Box 1625, Idaho Falls ID, 83414-6188, USA \\ Phone:1-208-526-4826,scott.ploger@inl.gov \\ ${ }^{1}$ Oak Ridge National Laboratory, P.O. Box 2008, Oak Ridge TN, 37831-6093, USA
}

\begin{abstract}
The AGR-1 experiment involved irradiation of 72 TRISO-coated particle fuel compacts to a peak burnup of 19.5\% FIMA with no in-pile failures observed out of $3 \times 10^{5}$ total particles. Irradiated AGR-1 fuel compacts have been cross-sectioned and analyzed with optical microscopy to characterize kernel, buffer, and coating behavior. Five compacts have been examined so far, spanning a range of irradiation conditions (burnup, fast fluence, and irradiation temperature) and including all four TRISO coating variations irradiated in the AGR-1 experiment. The cylindrical specimens were sectioned both transversely and longitudinally, then polished to expose between approximately 40-80 individual particles on each mount. The analysis focused primarily on kernel swelling and porosity, buffer densification and fracturing, buffer-IPyC debonding, and fractures in the IPyC and SiC layers. Characteristic morphologies have been identified, over 800 particles have been classified, and spatial distributions of particle types have been mapped. No significant spatial patterns were discovered in these cross sections. However, some trends were found between morphological types and certain behavioral aspects. Buffer fractures were found in approximately 23\% of the particles, and these fractures often resulted in unconstrained kernel swelling into the open cavities. Fractured buffers and buffers that stayed bonded to IPyC layers appear related to larger pore size in kernels. Buffer-IPyC interface integrity evidently factored into initiation of rare IPyC fractures. Fractures through part of the SiC layer were found in only three particles, all in conjunction with IPyC-SiC debonding. Compiled results suggest that the deliberate coating fabrication variations influenced the frequencies of IPyC fractures, IPyC-SiC debonds, and SiC fractures.
\end{abstract}

\section{INTRODUCTION}

The Advanced Gas Reactor (AGR) Fuel Development and Qualification Program was established to perform requisite research and development on tri-structural isotropic (TRISO)coated particle fuel to support deployment of a very high temperature reactor. Fuel irradiation experiments are being conducted at the Idaho National Laboratory (INL) to obtain data on fuel performance under irradiation, support fuel process development, qualify the fuel for normal operating conditions, provide irradiated fuel for accident testing, and support the development of fuel performance and fission product transport models. The first of these irradiation tests, designated AGR-1, ended in November 2009. The experiment completed 620 effective full power days of irradiation in the Advanced Test Reactor. A peak burnup of $19.5 \%$ fissions per initial metal atom (FIMA) was achieved with zero particle failures observed based on the measured fission gas releaseto-birth ratios [1].

The AGR-1 fuel particles and compacts were fabricated at Oak Ridge National Laboratory (ORNL) using 350- $\mu \mathrm{m}$ diameter mixed uranium oxide/uranium carbide kernels produced by Babcock and Wilcox, Inc. Kernels were coated with a $100-\mu \mathrm{m}$ 
thick porous pyrocarbon buffer, a $40-\mu \mathrm{m}$ inner pyrolytic carbon (IPyC) layer, a $35-\mu \mathrm{m}$ silicon carbide (SiC) layer, and a $40-\mu \mathrm{m}$ outer pyrolytic carbon (OPyC) layer. As shown in Figure 1, the particles were pressed into right cylindrical compacts that were nominally $25 \mathrm{~mm}$ in length and $12.4 \mathrm{~mm}$ in diameter, which contained approximately 4100 coated particles each. A baseline fuel type and three fuel variants were included in the AGR-1 irradiation. All kernels came from a single composite lot with a uranium enrichment of $19.7 \%$ [2]. Baseline fuel was fabricated using historic German coating process conditions, while Variant 1 had a higher IPyC deposition temperature, Variant 2 had a higher IPyC coating gas fraction, and Variant 3 had a lower $\mathrm{SiC}$ deposition temperature in conjunction with mixing an argon diluent into the hydrogen gas used to fluidize the particles [2].
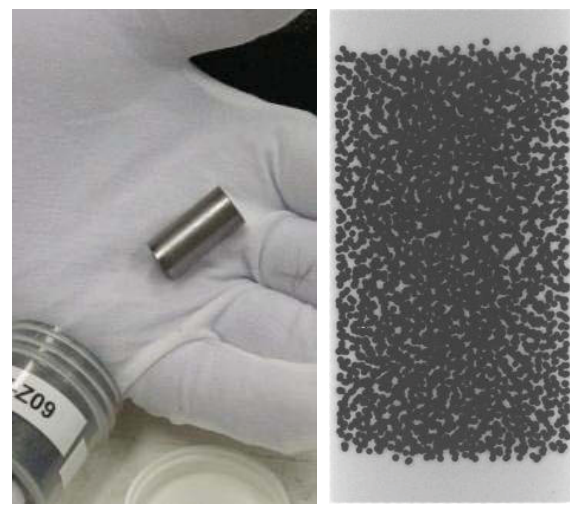

Fig. 1: Photograph (left) and x-radiograph (right) of an unirradiated AGR-1 fuel compact. Uranium oxide/uranium carbide kernels and non-fueled end caps are clearly visible in the $\mathrm{x}$-radiograph.

A total of 72 fuel compacts were irradiated in the AGR-1 test train [1]. Compacts were identified first by capsule number ( 1 through 6$)$, then by elevation in each stack ( 1 at the bottom through 4 at the top), and finally by stack number $(1,2$, or 3$)$. Compacts 2-1-3, 3-3-3, 4-1-3, 5-1-2, and 6-3-3 were examined at INL, while Compact 6-4-2 is being examined at ORNL. These compacts were chosen to span ranges of AGR-1 irradiation temperature and neutron exposure, as indicated in Table 1. Compacts were cross sectioned as illustrated in Figure 2. The central transverse Section 1 was mounted for grinding, along with the interior surfaces of longitudinal Sections 2 and 3. Each examined particle was denoted by experiment, by compact, by mount identifier, and by the order of imaging (e.g., AGR1-333-56T-013 in Figure 3).
Table 1: Calculated time-average volume-average temperature [3], time-average maximum temperature [3], burnup [4], and fast neutron fluence [4].

\begin{tabular}{|c|c|c|c|c|}
\hline $\begin{array}{c}\text { Compact } \\
\text { number } \\
\text { and fuel } \\
\text { type }\end{array}$ & $\begin{array}{c}\text { Time- } \\
\text { average } \\
\text { volume- } \\
\text { average } \\
\text { temp. } \\
(\mathrm{K})\end{array}$ & $\begin{array}{c}\text { Time- } \\
\text { average } \\
\text { maxi- } \\
\text { mum } \\
\text { temp. } \\
(\mathrm{K})\end{array}$ & $\begin{array}{c}\text { Average } \\
\text { burnup } \\
(\%\end{array}$ & $\begin{array}{c}\text { Fast } \\
\text { fluence } \\
\left(\mathrm{x} 10^{25}\right. \\
\left.\mathrm{n} / \mathrm{m}^{2}\right)\end{array}$ \\
\hline $\begin{array}{c}2-1-3 \\
\text { Variant 2 }\end{array}$ & 1261 & 1370 & 18.4 & 3.77 \\
\hline $\begin{array}{c}3-3-3 \\
\text { Baseline }\end{array}$ & 1327 & 1420 & 19.0 & 4.30 \\
\hline $\begin{array}{c}4-1-3 \\
\text { Variant 3 }\end{array}$ & 1348 & 1457 & 19.3 & 4.20 \\
\hline $\begin{array}{c}5-1-2 \\
\text { Variant 1 }\end{array}$ & 1281 & 1388 & 15.7 & 3.38 \\
\hline $\begin{array}{c}6-3-3 \\
\text { Baseline }\end{array}$ & 1379 & 1447 & 13.5 & 2.70 \\
\hline $\begin{array}{c}6-4-2 \\
\text { Baseline }\end{array}$ & 1281 & 1373 & 11.2 & 2.17 \\
\hline
\end{tabular}

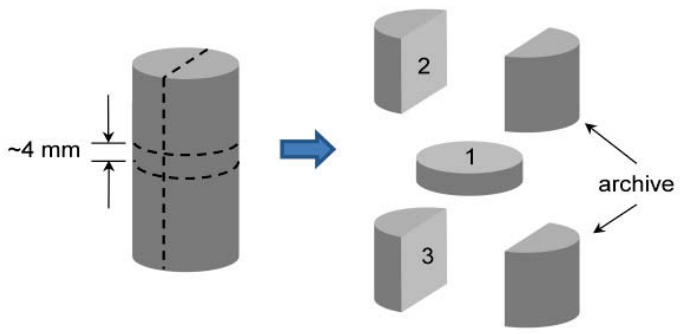

Fig. 2: Cutting diagram for AGR-1 compacts.

Microscopy of cross-sectioned compacts was intended to study kernel porosity and deformation, buffer layer degradation, $\mathrm{SiC}$ layer corrosion, fractures in TRISO layers and delaminations between them, and any deleterious interactions between the matrix and OPyC layer. Many of these objectives are also being pursued on epoxy-mounted groups of loose particles after compact deconsolidation, but compact cross sections provided the only opportunity to study matrix effects and any spatial variations in particle behavior. Microstructures and morphologies had to be preserved against preparation damage to discern any spatial patterns, so hot cell cutting, grinding, and polishing techniques had to be developed that reliably produced high quality sample surfaces. Preserving the vast majority of particle features also 
enabled characterizing sufficient particles for meaningful comparisons among AGR-1 compacts.

\section{MORPHOLOGICAL INVESTIGATIONS}

\section{II.A. Characteristic Morphologies}

Individual images were taken at high resolution of all particle cross sections with visible kernels in each mount. As particle images were examined, characteristic end-state morphologies came to be recognized. The most common feature was a radial gap between the buffer and IPyC layers where the buffer densified inward during irradiation. As shown in Figure 3, when the buffer and IPyC layers had debonded completely, the buffer and its enclosed kernel were not securely held inside the outer TRISO shells. While grinding through the sawdamaged thickness on each mount, fluid epoxy had to be vacuum-impregnated (back-potted) into these gaps as they were opened to stabilize loose buffers and kernels. In the absence of frequent back-potting, any dislodged kernels would quickly break into coarse abrasive fragments that would damage the mount by scoring the surface with deep scratches.

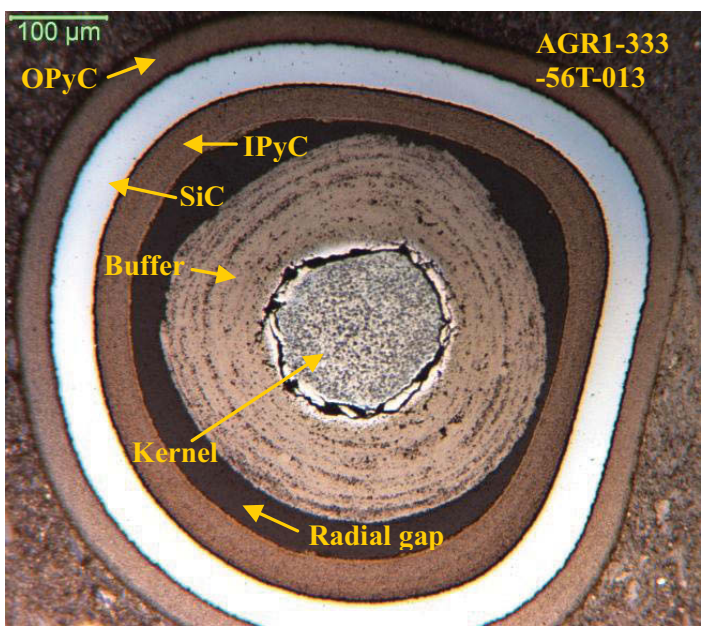

Fig. 3: Buffer and kernel that rotated before the radial gap was filled by back-potted epoxy.

In some particles with inward buffer densification, the radial buffer-IPyC gap was interrupted by regions where the buffer stayed firmly bonded to the IPyC layer. An example of such a particle is displayed in Figure 4. Many of these particles debonded along most of the interfacial circumference, while debonding was much less extensive on some other particles when the AGR-1 irradiation ended.
The rarest case was where a particle had no buffer-IPyC gap. In these cases, the buffer stayed bonded to the IPyC layer around the entire circumference. The buffers in these particles still evidently densified, but radially outward rather than inward. Kernels in these particles generally swelled to occupy the additional space. Kernels in these particles often had larger pores than seen within inwardly densified buffers.

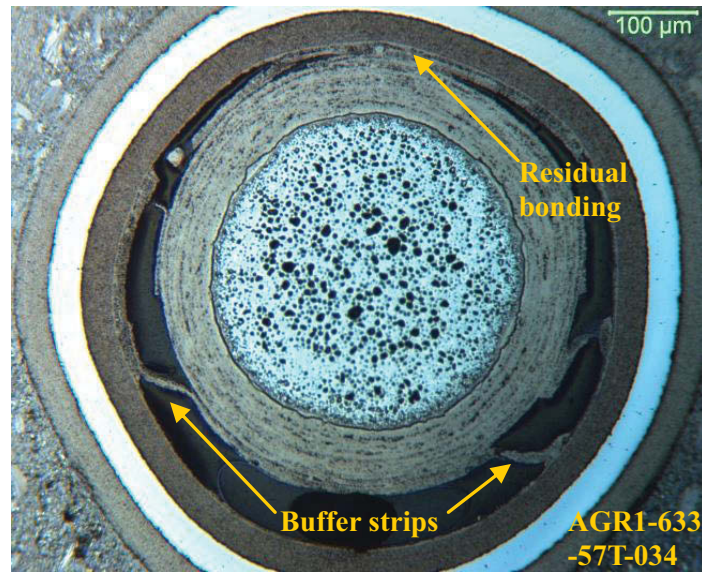

Fig. 4: Radial gap interrupted by residual bufferIPyC bonding along the interface.

A comprehensive scheme for classifying irradiated AGR-1 particles by morphology is presented with representative examples in Figure 5. Therein a radial buffer-IPyC gap around the entire circumference (completely detached buffer-IPyC interface) is called a Type A end-state morphology. Particles with fully bonded buffer and IPyC layers are termed Type B particles. Debonding along part of the buffer-IPyC interface is called a Type AB endstate morphology. Buffer fracturing was observed in Types A, B, and AB, which was often accompanied by kernel pore enlargement and kernel growth between buffer pieces. Other consequences of buffer fracturing could be quite different in the three basic types, as discussed in Section III. Six characteristic morphologies were used to classify irradiated AGR-1 particles, as displayed in Figure 5.

Firmly distinguishing between Types $\mathrm{A}$ and $\mathrm{AB}$ was difficult with only a two-dimensional view. In Type A particles, the possibility of local buffer-IPyC bonding cannot be eliminated for planes not visible in the micrograph. Furthermore, as illustrated in Figure 4, buffers did not always detach smoothly from IPyC layers, especially where bonding was locally strong. Patches of buffer occasionally remained attached to IPyC interiors in Type A particles. 


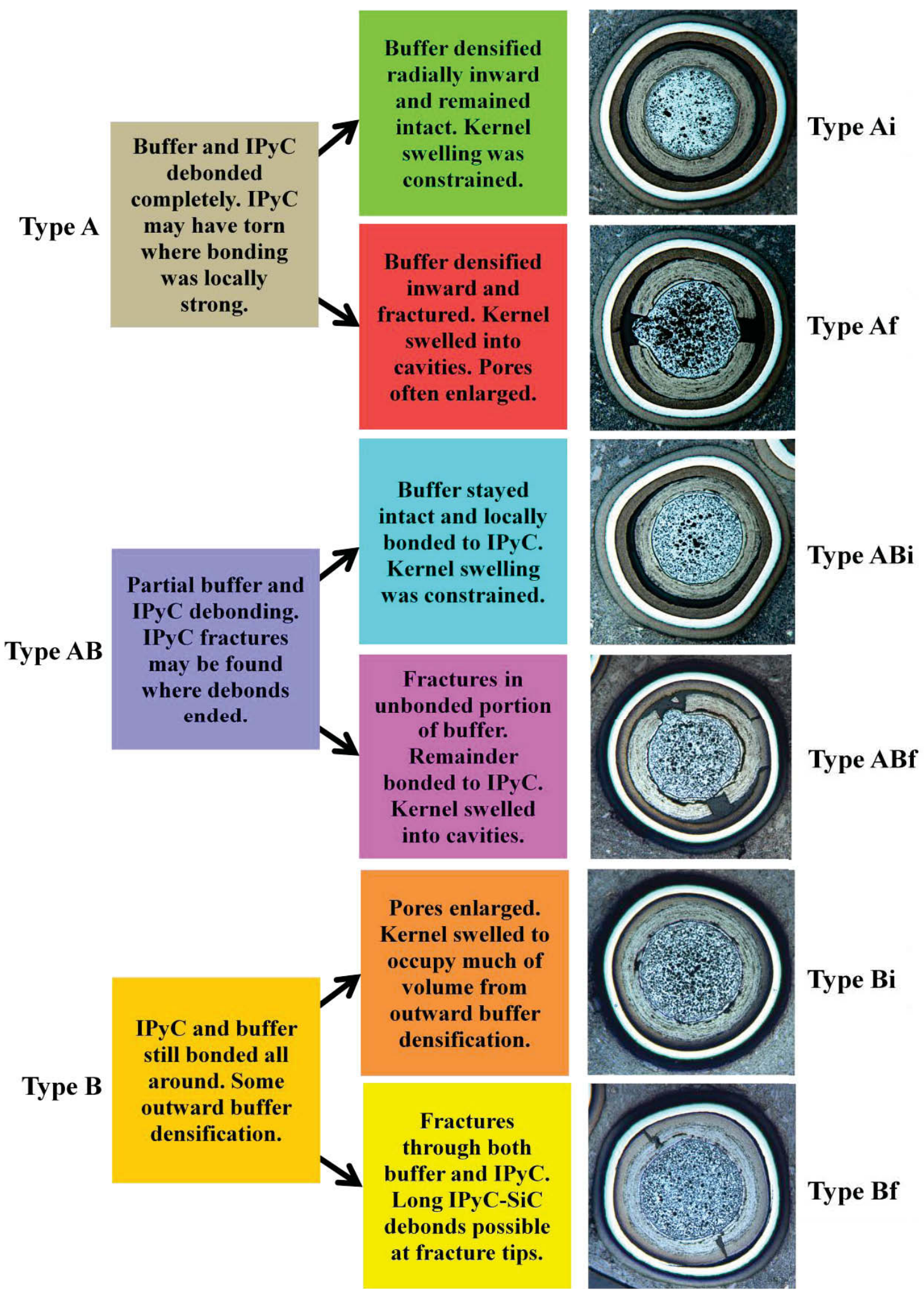

Fig. 5: Characteristic end-state morphologies and associated features observed in irradiated AGR-1 particles, where " $i$ " signifies an intact buffer and "f" signifies a fractured buffer. 
The colors in the middle column of Figure 5 were used to encircle the classified particles in the cross sections in order to map morphologies. An example map is provided in Figure 6, where the spatial distribution of colors appears random. This is typical of all AGR-1 transverse and longitudinal morphology maps. No obvious patterns were evident despite appreciable estimated gradients in temperature [3], some variation in calculated fast fluence [4], and significant variations in measured burnup [5] within individual irradiated AGR-1 compacts.

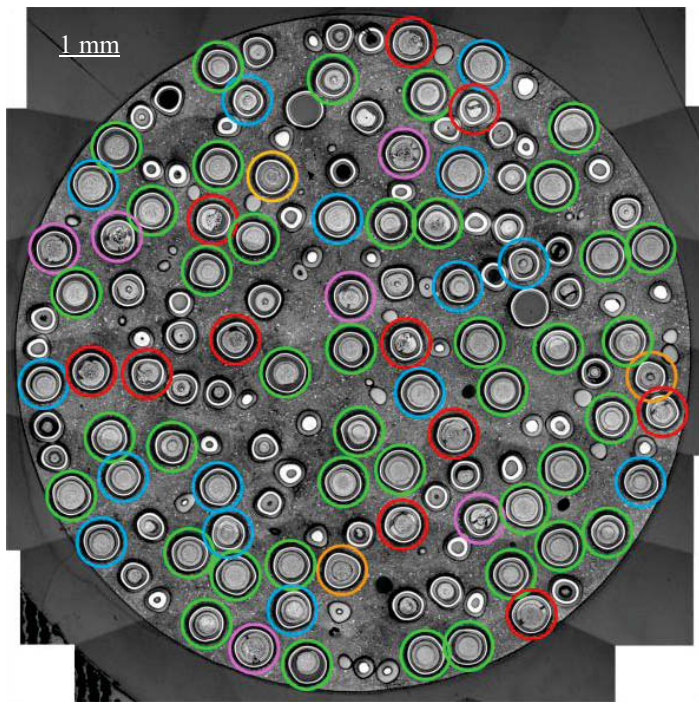

Fig. 6: Particle morphology map for the transverse cross section of Compact 3-3-3.

\section{II.B. Particle Type Frequencies}

Frequencies of morphological types varied among compacts as shown in Table 2. The most evident observation is regarding Compact 6-3-3, where somewhat more buffer fracturing was found (Type Af plus Type ABf) at the expense of Type Ai particles, relative to other compacts. Numbers of particles with fractured buffers in Table 2 were biased upward slightly because of how particles were selected for classification. High resolution images were only taken of particles showing visible kernel, but this selection method included several Type Af and Type ABf cases where small kernel portions intruded into buffer cavities perpendicular to the micrograph plane. Without such kernel intrusions into perpendicular buffer cavities, these particles would not otherwise have been classified because they were ground too far from mid-plane to expose the main kernel portion.
Table 2: Number of classified particles by type identified in each AGR-1 fuel compact.

\begin{tabular}{|c|c|c|c|c|c|c|c|}
\hline \multirow{2}{*}{ Compact } & \multicolumn{2}{|c|}{ Type A } & \multicolumn{2}{|c|}{ Type B } & \multicolumn{2}{|c|}{ Type AB } & \multirow{2}{*}{ Sum } \\
\hline & $\mathrm{Ai}$ & Af & $\mathrm{Bi}$ & $\mathrm{Bf}$ & $\mathrm{ABi}$ & $\mathrm{ABf}$ & \\
\hline $2-1-3$ & 107 & 15 & 7 & 2 & 44 & 31 & 206 \\
\hline $3-3-3$ & 38 & 9 & 3 & 0 & 17 & 8 & 75 \\
\hline $4-1-3$ & 95 & 8 & 10 & 0 & 31 & 13 & 157 \\
\hline $5-1-2$ & 123 & 14 & 3 & 2 & 39 & 24 & 205 \\
\hline $6-3-3$ & 72 & 31 & 17 & 2 & 33 & 32 & 187 \\
\hline \multirow[b]{2}{*}{ Totals } & 435 & 77 & 40 & 6 & 164 & 108 & \multirow[b]{2}{*}{830} \\
\hline & \multicolumn{2}{|c|}{512} & \multicolumn{2}{|c|}{46} & \multicolumn{2}{|c|}{272} & \\
\hline
\end{tabular}

Data from Table 2 were reconfigured according to the three basic particle types and normalized into percentages for presentation in Figure 7. Figure 7 makes it clear that buffer-IPyC debonding was very common in irradiated AGR-1 particles. Most images of Type $\mathrm{ABi}$ particles revealed that debonding occurred along much of their buffer-IPyC boundaries, so it appears that many Type ABi particles were transforming to Type Ai when the AGR-1 experiment was concluded. Figure 7 suggests that differences in neutron exposure and temperature among AGR-1 compacts had only minor influence on the extent of buffer-IPyC debonding. Variations in AGR-1 TRISO coatings also had no obvious impact on how much debonding occurred along interfaces between buffer and IPyC layers.

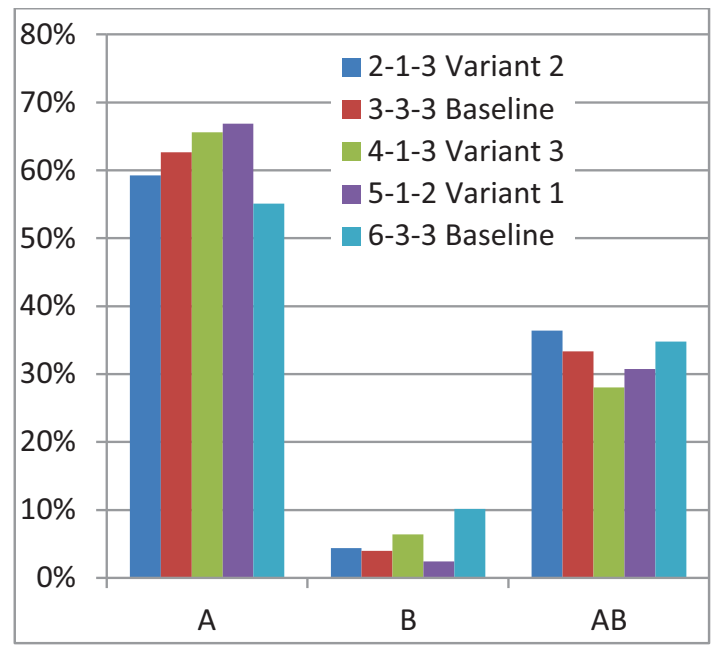

Fig. 7: Percentages by AGR-1 compact within each of the three basic particle types. 


\section{TRISO LAYER FRACTURES}

Zero in-pile particle failures were detected from abrupt fission gas releases during the AGR-1 experiment. However, irradiation-induced fractures of varying severity and frequency were found during ceramography in all TRISO layers except the OPyC layer. No OPyC fractures were observed. Even on the occasions when the carbonaceous compact matrix fractured during sample preparation, the fractures always diverted around the OPyC layers rather than propagating into them. Similarly, the only instances of matrix-OPyC debonding were attributed to sample preparation, especially sawing.

\section{III.A. Buffer Fractures}

Fractures were far more frequent in the irradiated AGR-1 buffers than in any other TRISO layer. As displayed in Figure 8 (data combined from Table 2), buffer fractures were seen on average in $23 \%$ of the 830 particles classified. However, as noted previously, the selection process biased the numbers of Types Af and ABf upward slightly, so Figure 8 percentages should be viewed in a relative sense.

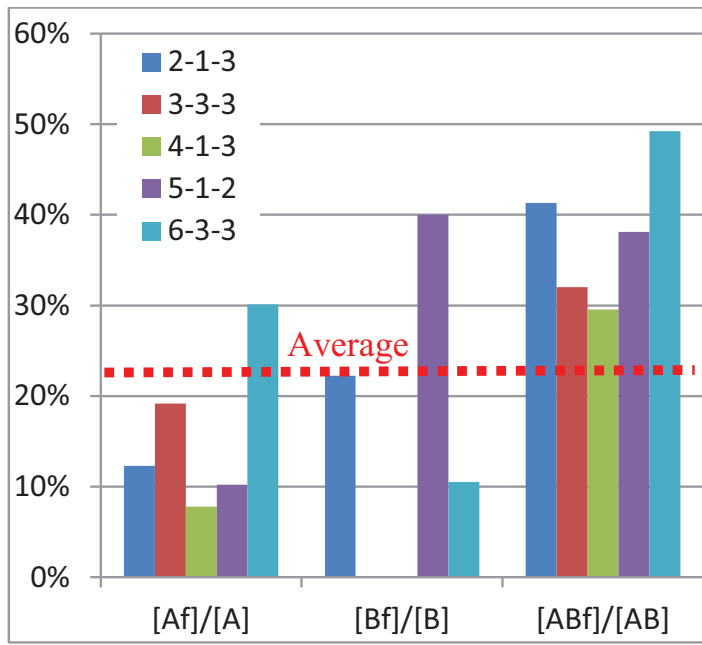

Fig. 8: Frequency of fractured buffers among basic types in irradiated AGR-1 compacts.

Figure 8 shows that buffer fractures were somewhat more frequent in Compact 6-3-3 and less common in Compact 4-1-3. Overall, however, the minor buffer fracture frequency differences among compacts are less striking than the frequency differences among particle types. Figure 8 reveals that buffer fractures occurred over twice as frequently in Type $\mathrm{AB}$ particles than in Type A particles. This general trend is seen in Figure 8 for all five compacts. The reason was not immediately apparent because buffer fractures have been thought to arise in both Type $\mathrm{A}$ and Type $\mathrm{AB}$ particles from buffer hoop stress created by the combination of inward buffer densification and outward kernel growth. The diametrically opposed buffer fractures shown in the Figure 5 examples for Type Af and Type ABf particles likely developed as illustrated in Figure 9, where one side fractured earlier and allowed preferential kernel growth into the initial cavity. Most of the Type Af and Type ABf particles showed more kernel growth into a cavity on one side. Fractured buffer surfaces from the process in Figure 9 typically were smooth and purely in the radial direction. These smooth radial fractures were much more common in Type Af buffers than in Type ABf buffers.

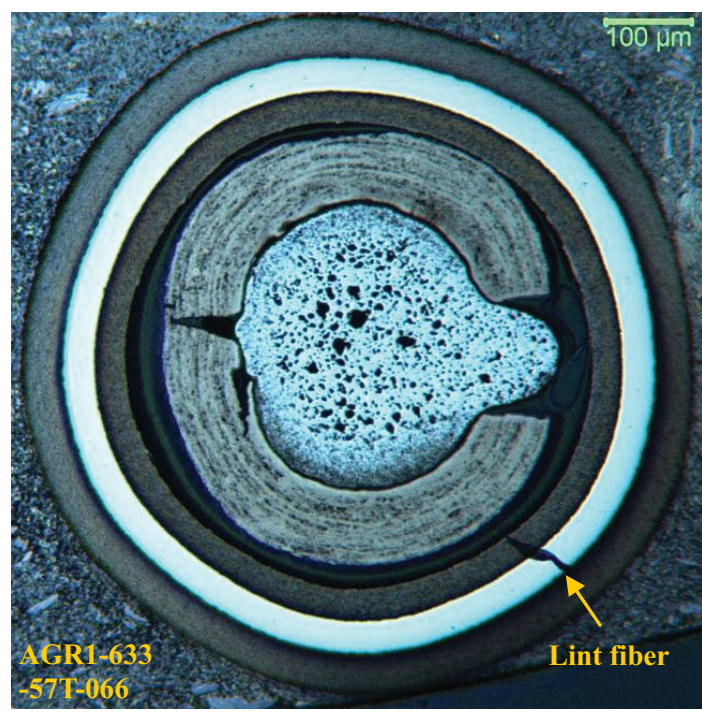

Fig. 9: Preferential kernel growth into a cavity from an early buffer fracture.

The Figure 9 fracture process cannot explain the increased buffer fractures in Type $A B$ particles, where a second mechanism may have dominated. Figure 10 shows that buffer fractures could be more complex than in Figure 9. These complex fractures often appear to have initiated tangentially at the kernel interface. The initially tangential buffer fractures evidently failed radially after propagating in a variety of directions. Such jagged buffer fracture surfaces were found much more frequently in Type ABf particles than Type Af particles. This process is still under investigation, but incipient tangential fractures found thus far in Type $A B$ buffers tended to be near the ends of buffer-IPyC debonds. 


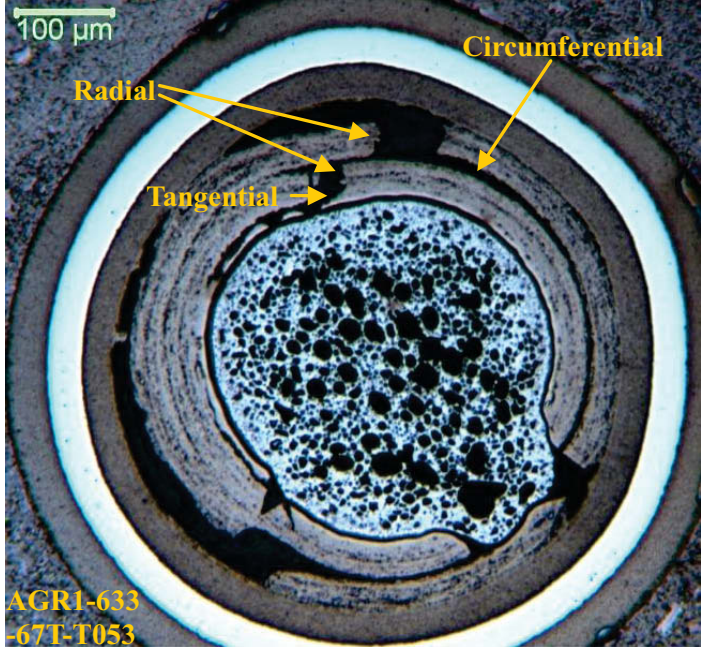

Fig. 10: Complex buffer fracture with a mixture of tangential, circumferential, and radial components.

\section{III.B. IPyC Fractures}

Fractures in irradiated AGR-1 IPyC layers were observed in a range of extents, from incipient to through-wall, as well as in a wide variety of circumstances. Figures 11 and 12 suggest that the IPyC layer could be torn during buffer-IPyC debonding at interfacial points where bonding was especially strong. Buffer fractures clearly were not essential for IPyC fractures. Similar behavior with buffer fracturing is shown in Figure 5 for the Type ABf example, where IPyC fractures were found immediately adjacent to the circumferential region that still had a bonded buffer-IPyC interface.

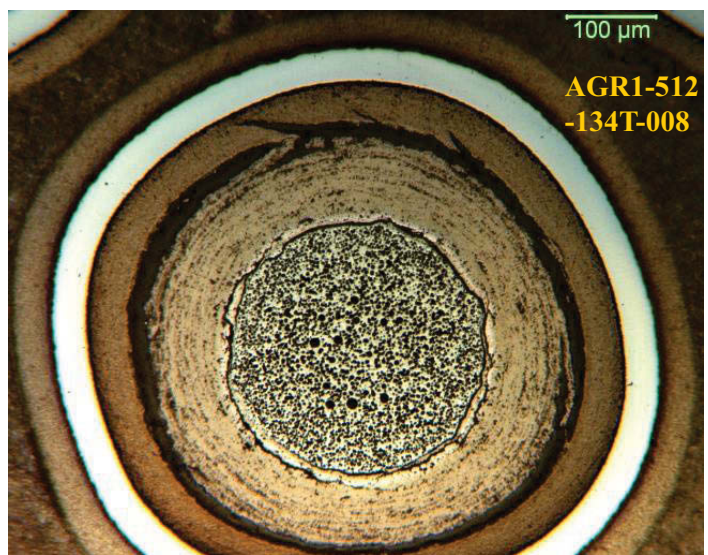

Fig. 11: IPyC tears at top from buffer debonding.

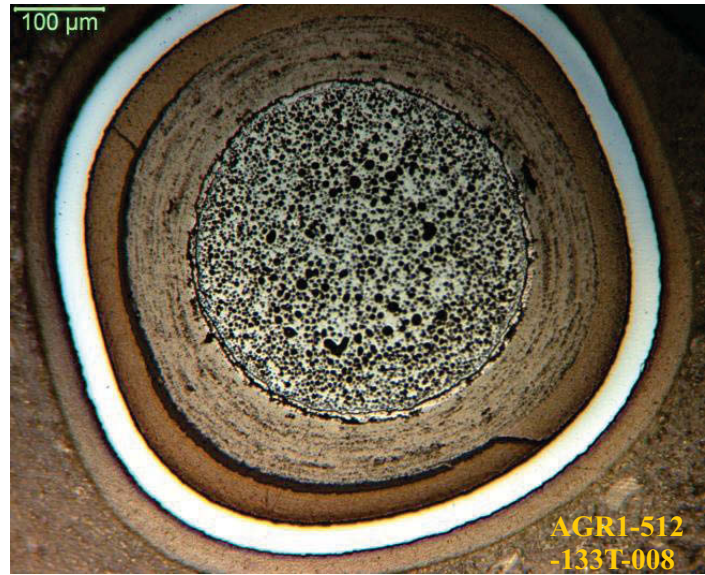

Fig. 12: IPyC fractures near ends of buffer debonds.

Further evidence of the importance of bufferIPyC bonding to IPyC fracturing is provided at the top of Figure 13. In this Type AB particle, the left IPyC fracture split a Type B-like region where the buffer and IPyC layers were still bonded, so this IPyC fracture may not have been possible without the adjacent buffer fracture.

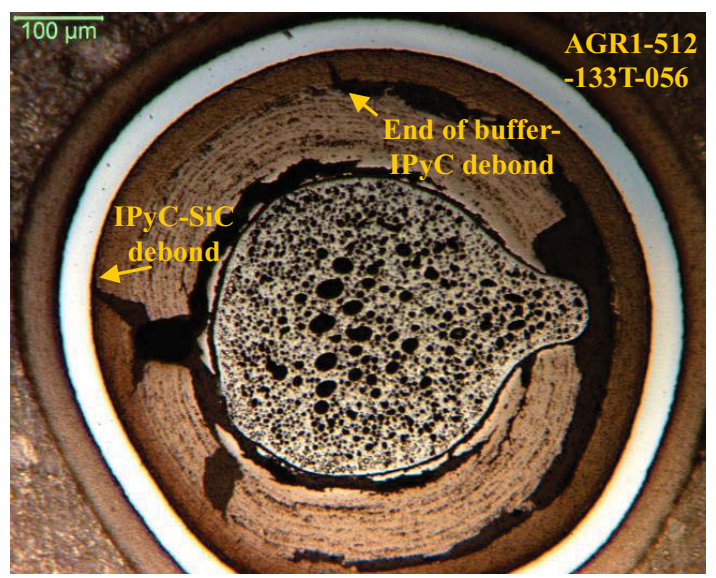

Fig. 13: IPyC fractures near regions still bonded to the buffer layer.

Figure 13 shows an incipient IPyC-SiC debond at the tip of the left IPyC fracture. Much more IPyC$\mathrm{SiC}$ debonding is displayed for a Type $\mathrm{B}$ particle in Figure 14 at all three IPyC fracture tips. These large IPyC-SiC debonds extended symmetrically on both sides of the radial IPyC fractures. All three IPyC fractures evidently propagated from buffer fractures. 


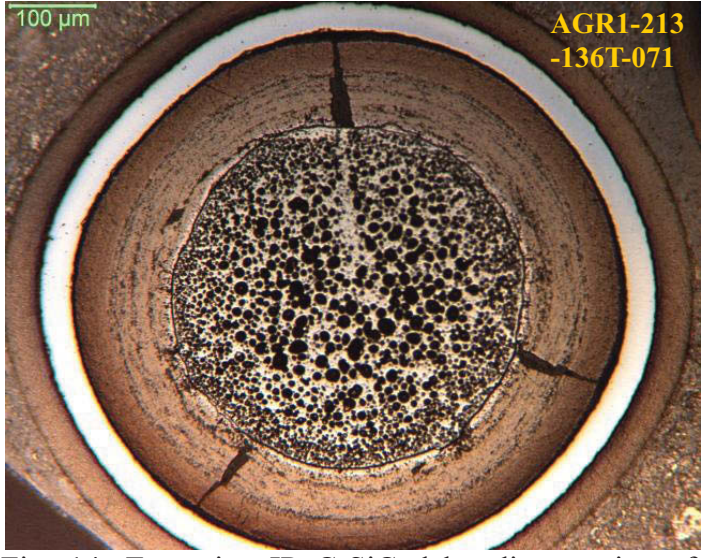

Fig. 14: Extensive IPyC-SiC debonding at tips of IPyC fractures in a Type Bf particle.

IPyC fracture statistics are given in Table 3, where particles with both partial and through-IPyC fractures were counted as only having the more severe through-IPyC fracture. Minor tears from buffer debonding happened in a small percentage of Types Ai, Af, and ABi particles, while through-IPyC fractures in these types were even rarer. No partial or through-wall IPyC fractures were found in Type Bi particles, but all six Type Bf particles had throughIPyC fractures that coincided with buffer fractures.

Table 3: Summary of IPyC fracture data from all classified particles in five AGR-1 compacts.

\begin{tabular}{|c|c|c|c|}
\hline \multirow{2}{*}{$\begin{array}{c}\text { Particle } \\
\text { Type }\end{array}$} & $\begin{array}{c}\text { Particles } \\
\text { with } \\
\text { fractures }\end{array}$ & $\begin{array}{c}\text { Number of } \\
\text { particles in } \\
\text { each type }\end{array}$ & $\begin{array}{c}\text { Fracture } \\
\text { frequency }\end{array}$ \\
\cline { 2 - 4 } & \multicolumn{2}{|c|}{ Particles with partial IPyC fractures } \\
\hline $\mathrm{Ai}$ & 7 & 435 & $1.6 \%$ \\
\hline $\mathrm{Af}$ & 4 & 77 & $5.2 \%$ \\
\hline $\mathrm{Bi}$ & 0 & 40 & $0.0 \%$ \\
\hline $\mathrm{Bf}$ & 0 & 6 & $0.0 \%$ \\
\hline $\mathrm{ABi}$ & 2 & 164 & $1.2 \%$ \\
\hline $\mathrm{ABf}$ & 8 & 108 & $7.4 \%$ \\
\hline $\mathrm{Total}$ & 21 & 830 & $2.5 \%$ \\
\hline & Particles with fractures through IPyC \\
\hline $\mathrm{Ai}$ & 2 & 435 & $0.5 \%$ \\
\hline $\mathrm{Af}$ & 0 & 77 & $0.0 \%$ \\
\hline $\mathrm{Bi}$ & 0 & 40 & $0.0 \%$ \\
\hline $\mathrm{Bf}$ & 6 & 6 & $100.0 \%$ \\
\hline $\mathrm{ABi}$ & 2 & 164 & $1.2 \%$ \\
\hline $\mathrm{ABf}$ & 19 & 108 & $18.1 \%$ \\
\hline $\mathrm{Total}$ & 29 & 830 & $3.5 \%$ \\
\hline
\end{tabular}

Table 3 shows that both partial and especially through-wall IPyC fractures were much more likely in Type $\mathrm{ABf}$ particles than in Type $\mathrm{ABi}$ particles. IPyC fractures that propagated directly from a buffer fracture, such as in the left portion of Figure 13, contributed a bit to this trend. However, most IPyC fractures in Type ABf particles were located far from buffer fractures, as shown in the Type ABf example (Figure 5). Instead of buffer fractures causing most IPyC fractures in Type ABf particles, locally strong buffer-IPyC bonding may have been involved in initiating fractures in Type $A B$ buffers as well as in initiating IPyC fractures. Note that Type AB buffer fractures and IPyC fractures could have initiated at different times at different azimuths as the apparently uneven buffer-IPyC bond delaminated.

Figure 15 presents the frequencies of IPyC fractures among the five AGR-1 compacts. Results vary substantially, particularly for fractures that penetrated the entire IPyC layer. Although values were similar for Compacts 2-1-3 (Variant 2), 3-3-3 (Baseline), and 6-3-3 (Baseline), particles in Variant 1 Compact 5-1-2 contained a much higher incidence of through-IPyC fractures (19 of 205 classified particles), which may be related to the lower IPyC density in Variant 1 [2]. Zero throughIPyC fractures were found in Variant 3 Compact 4-1-3 (157 particles) despite its higher irradiation temperatures and neutron exposure (Table 1).

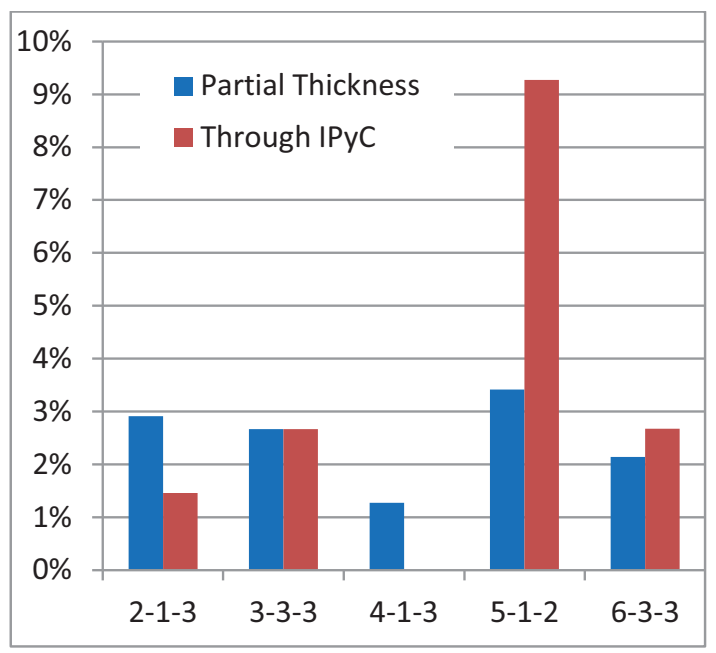

Fig. 15: Percentages of particles with IPyC fractures among irradiated AGR-1 compacts.

\section{III.C. SiC Fractures}

$\mathrm{SiC}$ fractures were found in only three classified AGR-1 particles from the five cross-sectioned fuel compacts. None of these fractures were determined to have breached the entire $\mathrm{SiC}$ layer thickness during irradiation.

One cross-sectioned particle exhibited abnormal $\mathrm{SiC}$ structure and appeared to contain foreign material between the IPyC and SiC layers. This 
particle also had $\mathrm{SiC}$ fractures, as displayed in Figure 16. The lenticular bulge between the IPyC exterior and $\mathrm{SiC}$ interior on the right side is characteristic of a soot inclusion, which occurs when over-fluidized particles pick up carbon soot from the walls of the coating chamber. A soot inclusion can also result in a region of porous $\mathrm{SiC}$ where $\mathrm{SiC}$ infiltrates the low density soot during deposition. This anomaly has been termed a "gold spot" because of the optical appearance of the defective SiC after removal of the OPyC layer. Particles with soot inclusions were observed during characterization of the pre-irradiated fuel particles with defect frequencies equal to 1-4 particles per compact [6].

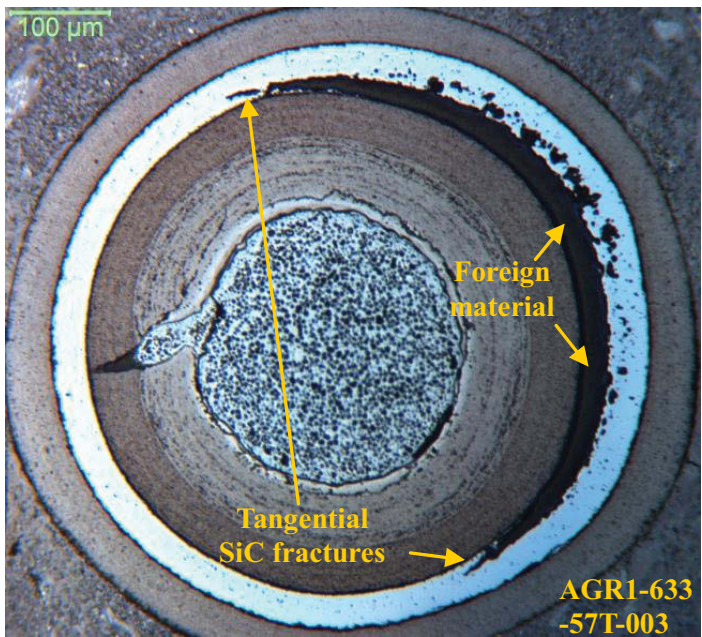

Fig. 16: Tangential SiC fractures bordering a probable soot inclusion.

The tangentially oriented $\mathrm{SiC}$ fractures in Figure 16 apparently started where the IPyC and $\mathrm{SiC}$ were allowed to bond by the absence of foreign material. Buffer and IPyC layers stayed bonded around the entire interface in this Type $\mathrm{Bf}$ particle. The fracture through the buffer and IPyC layer on the left side was not clearly caused by the foreign material. This aligned buffer-IPyC fracture resembles those in Figure 14 with two exceptions. The kernel swelled into the buffer cavity, which was narrower than most buffer cavities in Type Af and Type ABf particles, and the IPyC-SiC debond at this crack tip was much shorter than at all three crack tips in Figure 14.

There is no indication that any foreign material was present between the IPyC and SiC layers in the remaining two classified particles with $\mathrm{SiC}$ fractures. The particle with the most $\mathrm{SiC}$ fractures is presented in Figure 17. It strongly resembles the Type $\mathrm{Bf}$ particle in Figure 14 except for the pair of $\mathrm{SiC}$ fractures that were symmetrically located around each of the two buffer-IPyC fractures. Propagation of the rightmost $\mathrm{SiC}$ fracture may have stopped when IPyC-SiC debonding progressed beyond this azimuth toward the top of the image.

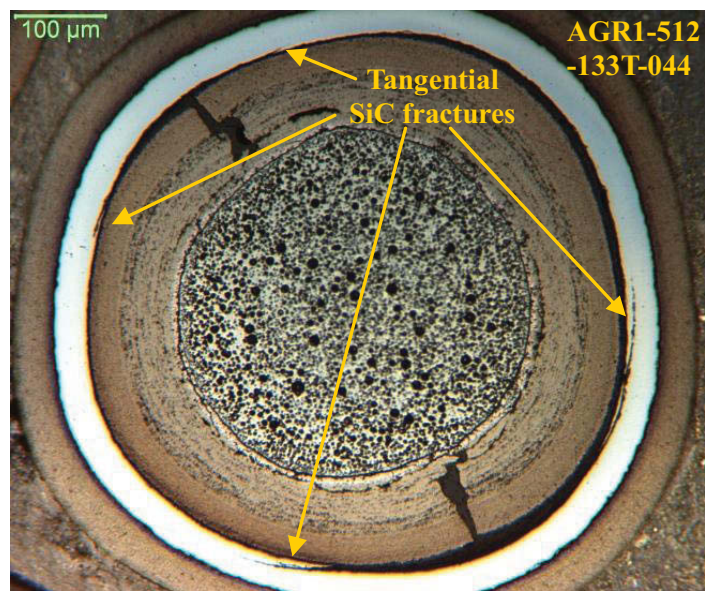

Fig. 17: Pairs of $\mathrm{SiC}$ fractures symmetrically positioned around two buffer-IPyC fractures.

The $\mathrm{SiC}$ fracture in Figure 18 is in yet another Type Bf particle. IPyC and $\mathrm{SiC}$ layers debonded along most of the interface at this plane. The $\mathrm{SiC}$ fracture apparently began where the IPyC-SiC bond was still intact.

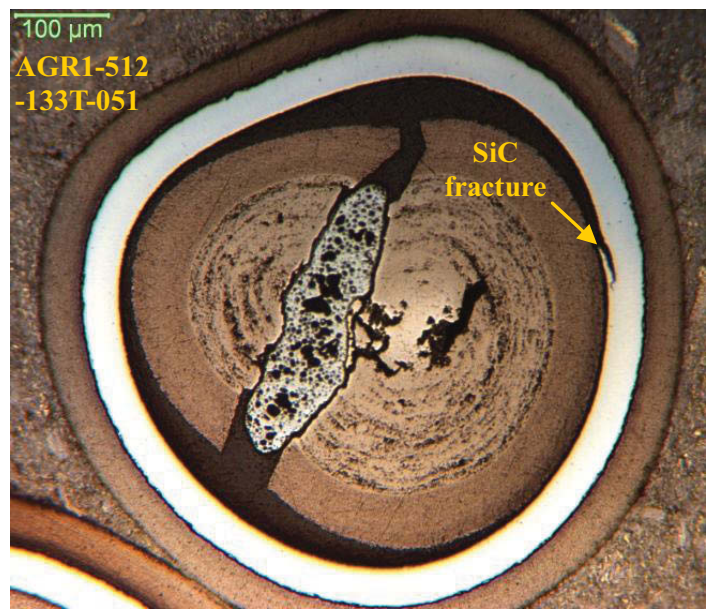

Fig. 18: Tangential $\mathrm{SiC}$ fracture in a distorted particle (cross section located far from mid-plane).

IPyC-SiC debonds and $\mathrm{SiC}$ fractures within the five compacts are grouped in Table 4 . The particle with foreign material was too rare to correlate with coating variations. However, Table 4 infers that $\mathrm{SiC}$ anomalies were more frequent in Compact 5-1-2 (Variant 1). This finding is likely related to the much 
larger frequency of through-IPyC fractures in Compact 5-1-2 revealed in Figure 15.

Table 4: $\mathrm{SiC}$ anomalies in classified particles from five cross-sectioned AGR-1 compacts.

\begin{tabular}{|c|c|c|c|c|}
\hline \multirow[b]{2}{*}{ Compact } & \multicolumn{2}{|c|}{ Normal particles } & \multicolumn{2}{|c|}{ Foreign material } \\
\hline & $\begin{array}{l}\text { With } \\
\text { IPyC- } \\
\text { SiC } \\
\text { debond }\end{array}$ & $\begin{array}{c}\text { With } \\
\text { SiC } \\
\text { fracture }\end{array}$ & $\begin{array}{l}\text { With } \\
\text { IPyC- } \\
\text { SiC } \\
\text { debond }\end{array}$ & $\begin{array}{c}\text { With } \\
\text { SiC } \\
\text { fracture }\end{array}$ \\
\hline $2-1-3$ & 2 & 0 & 0 & 0 \\
\hline $3-3-3$ & 0 & 0 & 0 & 0 \\
\hline $4-1-3$ & 0 & 0 & 0 & 0 \\
\hline $5-1-2$ & 9 & 2 & 0 & 0 \\
\hline $6-3-3$ & 1 & 0 & 1 & 1 \\
\hline
\end{tabular}

Based on the preceding discussion, a tendency is apparent for $\mathrm{SiC}$ fractures to be more likely in particles with debonding along the IPyC-SiC interface. Figure 19 indicates that IPyC fractures, IPyC-SiC debonds, and $\mathrm{SiC}$ fractures were far more likely in Type Bf particles than in any other type. Although Type Bf particles represented less than 1\% of the classified particles, they contained almost $40 \%$ of the IPyC-SiC debonds and $100 \%$ of the $\mathrm{SiC}$ fractures. The absence of $\mathrm{SiC}$ fractures in the eight Type ABf particles with IPyC-SiC debonds may be related to the short extents of debonding found at the tips of the IPyC fractures.

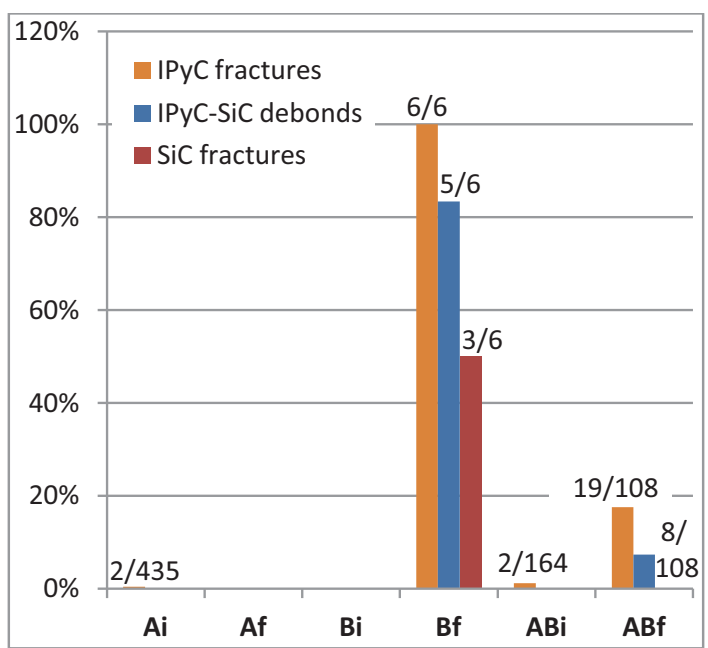

Fig. 19: Frequencies of IPyC fractures, IPyC-SiC debonds, and $\mathrm{SiC}$ fractures by type among the 830 classified AGR-1 particles.

\section{KERNEL BEHAVIOR}

\section{IV.A. Kernel Swelling}

The most conspicuous sign of kernel swelling was growth into fractured buffer cavities, as already shown in Figures 9, 10, 13, 16, and 18. Cavities in Figures 16 and 18 were narrow, which infers that kernels expanded into small spaces if those were the only open spaces available. Kernel growth could be extensive in the absence of buffer constraint, especially on planes where buffer pieces were separated. Alternatively, Figure 20 shows one of many cases where kernel growth into a buffer cavity was partially inhibited by a thin portion of buffer material. In all of these cases, the amount of constraint imposed by the adjacent buffer clearly had appreciable influence on local kernel growth.

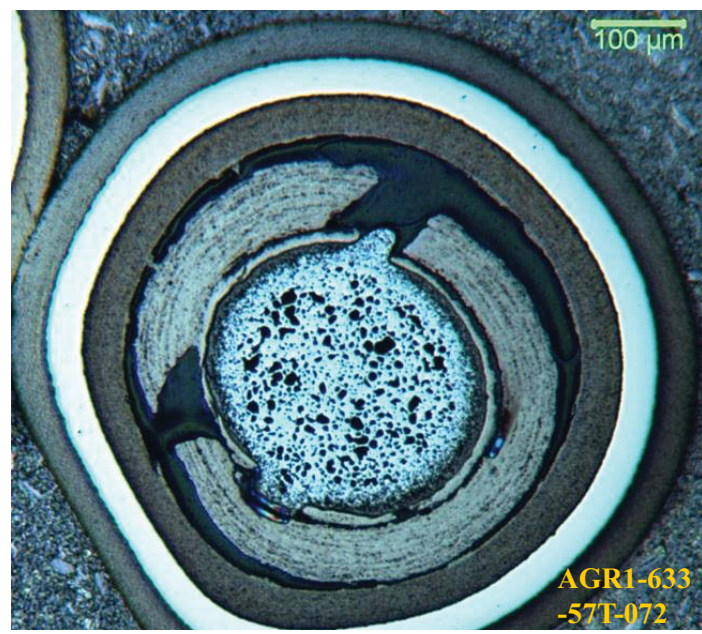

Fig. 20: Kernel growth blocked by buffer fragments.

\section{IV.B. Pore Enlargement}

Kernel growth into buffer cavities often was accompanied by pore enlargement. In a side-by-side comparison, Figure 21 contrasts the larger kernel pores inside a fractured buffer to those inside an intact buffer. This indicates that more pore enlargement occurred in the Particle 063 kernel after buffer fracturing than in the Particle 067 kernel (surrounded by an intact buffer). 


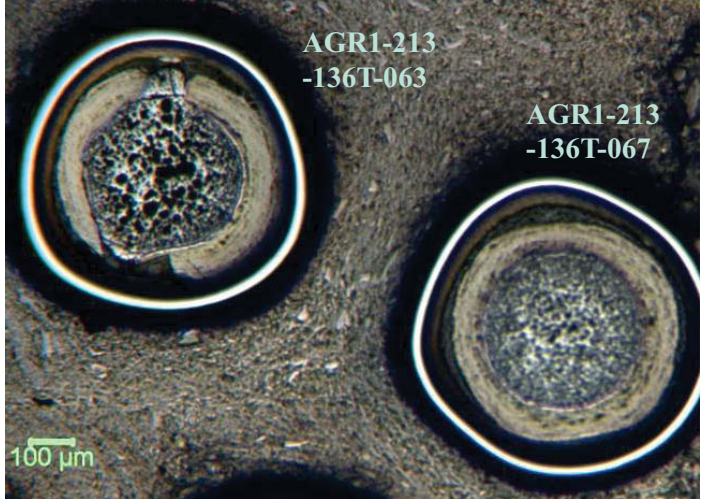

Fig. 21: Larger kernel pores inside a fractured buffer than inside a nearby kernel where swelling was fully constrained by the buffer.

Pore sizes were not always so different inside fractured and intact buffers, even within this same fuel compact, as demonstrated in Figure 22. One possible explanation is that the buffer in Particle 063 may have fractured earlier than the buffer in Particle 032, which also is supported by observing more kernel growth into buffer cavities in Particle 063 than in Particle 032. Growth in all four kernels in these two figures would have been constrained to nearly the same extent until buffer fracturing occurred.

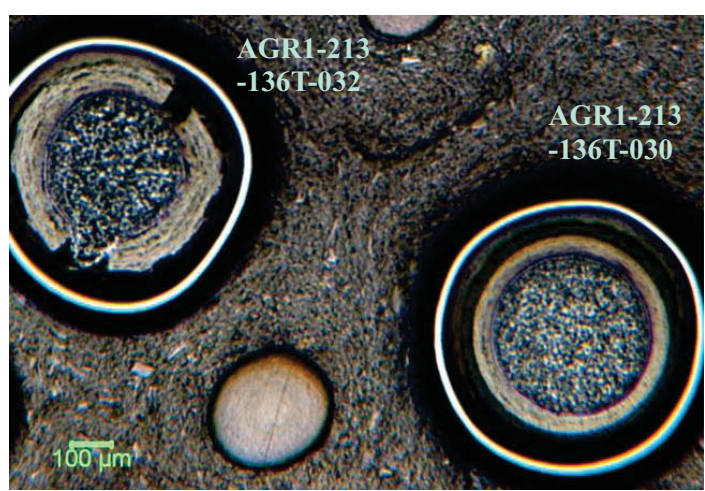

Fig. 22: Kernel pores within a fractured buffer that were only slightly larger than inside an intact buffer.

Figure 23 presents one of several side-by-side examples where pores were larger in Type B particles than in nearby particles with fractured buffers. The additional pore enlargement in Type B particles apparently reflects even less constraint on kernel swelling than imposed by fractured buffers. Type B buffers remained bonded to the IPyC layers and densified outward, imposing little or no constraint on kernels throughout the AGR-1 experiment. Buffer fracturing was not necessary for substantial pore enlargement in this Type Bi particle.

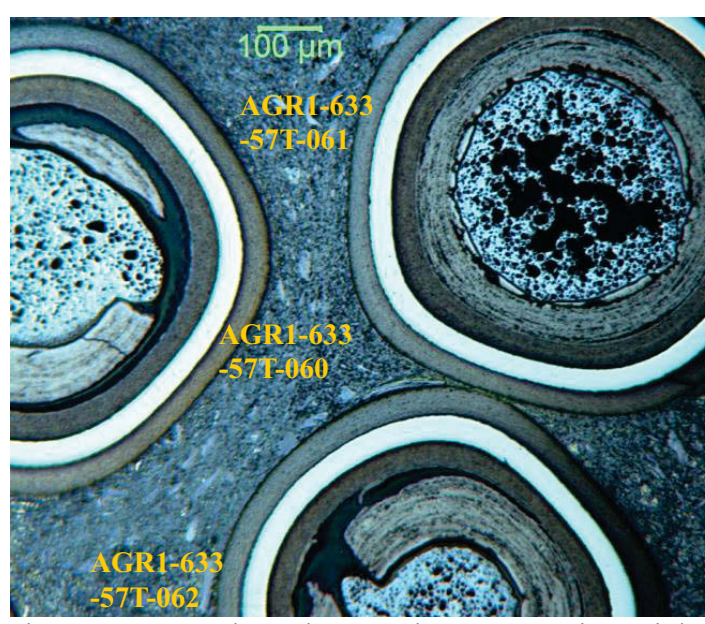

Fig. 23: Larger kernel pores in a Type Bi particle (upper right) than in two adjacent Type $\mathrm{AB}$ particles with fractured buffers.

\section{IV.C. Forthcoming Efforts}

Although qualitative trends on kernel swelling and pore behavior can be established by comparing images, understanding would be enhanced by quantitative studies. Quantitative information also appears essential for assessing any influences of irradiation temperature and neutron exposure. An effort has begun at INL to measure images taken on large particle ensembles from each of three compacts for assessments of kernel swelling, pore behavior, and buffer densification.

Two-dimensional particle cross sections are fundamentally limited for describing complicated three-dimensional structures. Two efforts have been initiated to better quantify kernel swelling and buffer densification, along with improving visualization of fracture behavior in TRISO coating layers. X-ray tomography is being performed on individual particles from deconsolidated AGR-1 compacts at ORNL. This will provide three-dimensional views of kernel and coating behavior that can be compared with existing two-dimensional data. Ensembles of at least 50 deconsolidated particles are also being mounted and will be ground, polished, and characterized at multiple levels. Besides providing more two-dimensional views of each particle for features such as fracture patterns in coating layers, this approach will avoid the staggered particle elevations in compact cross sections and should improve dimensional determinations for nonconcentric kernels and buffers. It may also help to mitigate other geometry-related effects, such as ranges of fabrication sizes. 
Post-irradiation examination results from AGR-1 particles will be incorporated into modeling studies. These modeling studies will help to provide mechanistic insights into the morphological changes that occurred within AGR-1 particles during irradiation.

Finally, detailed characterization of the irradiated particles is also being performed using scanning and tranmission electron microscopy with elemental analysis in order to better understand the affects of irradiation on kernel and coating microstructures and evaluate mechanisms of fission product migration through the coating layers. Results from these analyses will be presented separately.

\section{CONCLUSIONS}

Careful sample preparation allowed microscopic examinations of 830 irradiated TRISO particles within cross sections of five AGR-1 compacts. Detailed images of so many particles supported development of a comprehensive classification system that fostered comparative insights on many aspects of internal behavior.

No significant spatial patterns were revealed within compact cross sections by mapping the endstate characteristic morphological types.

Particles were classified primarily by the extent of buffer-IPyC bonding, where debonding appeared driven by inward buffer densification. Particles that had completely debonded along the buffer-IPyC interface were most numerous. Particles with fully bonded buffer and IPyC layers were rare. Particles with partial debonding were found with intermediate frequency. The relative proportions of these three basic types were not strongly influenced by differences among AGR-1 compacts in irradiation temperature or neutron exposure.

Particles were classified secondarily by buffer integrity. Over three-fourths of the buffers remained intact. Buffer fracturing was over twice as frequent in particles with partial buffer-IPyC debonding than with full debonding.

In particles with partial buffer-IPyC debonding, IPyC fractures tended to be found where bufferIPyC debonding terminated. IPyC fractures also were much more likely in particles with partial buffer-IPyC debonding when buffers fractured.

A buffer fracture with full buffer-IPyC bonding evidently always induced an IPyC fracture.

Fractures through the entire IPyC layer were more frequent in particles with partial buffer-IPyC debonding than in particles with complete debonding.
IPyC fracture frequency correlated with specific fabrication variations, with no through-IPyC fractures in the Variant 3 compact and by far the most in the Variant 1 compact with the lowest IPyC density.

$\mathrm{SiC}$ layers fractured very rarely and only partway through the thickness. Their formation was apparently influenced by the frequency of IPyC fractures and by the extent of IPyC-SiC debonding at IPyC fracture tips. SiC fractures may also have been encouraged when foreign material was present between the IPyC and SiC layers.

More kernel swelling and larger kernel pores tended to be found where less constraint was imposed by buffer layers.

\section{REFERENCES}

[1] S.B. Grover, Completion of the First NGNP Advanced Gas Reactor Fuel Irradiation Experiment, AGR-1, in the Advanced Test Reactor," Paper 104, Proceedings HTR-2010, Prague, Czech Republic, October 18-20, 2010.

[2] J.T. Maki, AGR-1 Irradiation Experiment Test Plan, INL/EXT-05-00593, Rev. 3, October 20, 2009.

[3] G.L. Hawkes, Idaho National Laboratory Engineering Calculations and Analysis Report 968, Rev. 2, AGR-1 Daily As-run Thermal Analyses, January 25, 2012.

[4] J.W. Sterbentz, Idaho National Laboratory Engineering Calculations and Analysis Report 958, Rev. 1, JMOCUP As-run Daily Depletion Calculation for the AGR-1 Experiment in ATR B-10 Position, August 11, 2011.

[5] J.M. Harp, Idaho National Engineering Laboratory Engineering Calculations and Analysis Report 1652, Analysis of Individual Compact Fission Product Inventory and Burnup for the AGR-1 TRISO Experiment Using Gamma Spectrometry, September 2011.

[6] J.D. Hunn and R.A. Lowden, Data Compilation for AGR-1 Baseline Coated Particle Composite LEU01-46T, ORNL/TM-2006/019, April 2006.

\section{ACKNOWLEDGMENTS}

This work was supported by the U.S. Department of Energy, Office of Nuclear Energy, under the Next Generation Nuclear Plant Project. 